\title{
COOPERATION AMONG LARVE OF A WILD TYPE STRAIN OF DROSOPHILA MELANOGASTER
}

\author{
M. J. KEARSEY \\ Agricultural Research Council Unit of Biometrical Genetics \\ Department of Genetics, University of Birmingham
}

Received 9.xi.64

THERE is at present a large body of evidence to show that increasing the density of a population brings about competition among individuals and so lowers the proportion of zygotes which reach maturity. Mather (196r), however, has suggested that at low densities the individuals may in fact cooperate in maintaining the minimal activity necessary to prevent the environment becoming unsuitable to all, and it was thought that such an effect might well be demonstrated in under-populated fly cultures. Lewontin (1955) and Lewontin and Matsuo (1963) have reported results consistent with the cooperation hypothesis and the present experiments provide further evidence and relate cooperation to fungal contamination of fly cultures.

An Oregon stock of Drosophila melanogaster, inbred in this laboratory for some $25^{\circ}$ generations was used and all experiments were carried out on normal yeasted oatmeal medium at $25^{\circ} \mathrm{C}$. Large numbers of eggs were collected over a 2-hour period, and transferred to the experimental tubes at varying densities. The metric used was the percentage of eggs developing into adults.

Preliminary experiments showed no significant change in viability throughout the range 1-20o eggs per tube, i.e. there was no evidence for cooperation or competition. The lack of positive evidence for cooperation was not, however, unexpected since precautions were taken in preparing the medium to keep fungal contamination to a minimum, and it is contamination that would make the need for cooperation greater.

In the following experiments fungal contamination, in the form of a strain of Penecillium isolated from old fly cultures, was deliberately introduced into the experimental vials. Spore suspensions from this strain, diluted to an arbitrary hæmocytometer count of 43 spores, were dispensed from a I ml. pipette at the rate of I drop per tube before yeasting.

To determine the range of densities over which cooperation might be acting, a series of tubes containing from $I$ to 200 eggs were set up and the results from this suggested that any increase in viability due to cooperation was occurring within the range $1-20$ eggs per tube. The three experiments now to be described were designed to explore this range more accurately.

In the first experiment egg densities of 2, 4, 6, 8, 12, 16 and 20 per tube were used. Each density was replicated in this and the next two experiments so that the product of density $\times$ replicates was approximately the same in all cases within an experiment. The adult survivals at these densities are shown in table $I$ and graphically in fig. I (expt. I). It will be seen that the relationship between survival and density is approximately that expected with cooperation at low densities and competition at higher densities. An analysis of variance on the data transformed to angles, however, shows 
TABLE I

Adult emergence summed over all replicates at each density for experiment $I$

\begin{tabular}{|c|c|c|c|c|}
\hline Density & $\begin{array}{c}\text { No. of } \\
\text { replicates }\end{array}$ & $\begin{array}{c}\text { Total } \\
\text { no. of } \\
\text { eggs }\end{array}$ & $\begin{array}{c}\text { No. of } \\
\text { emerging adults }\end{array}$ & $\begin{array}{c}\text { Per cent. } \\
\text { emergence }\end{array}$ \\
\hline 2 & 48 & 96 & 17 & $17 \cdot 7$ \\
4 & 24 & 96 & 27 & $28 \cdot 1$ \\
6 & 16 & 96 & 25 & $26 \cdot 0$ \\
8 & 12 & 96 & 25 & $26 \cdot 0$ \\
12 & 8 & 96 & 17 & $17 \cdot 7$ \\
16 & 6 & 96 & 15 & $15 \cdot 6$ \\
20 & 5 & 100 & 18 & $18 \cdot 0$ \\
\hline
\end{tabular}

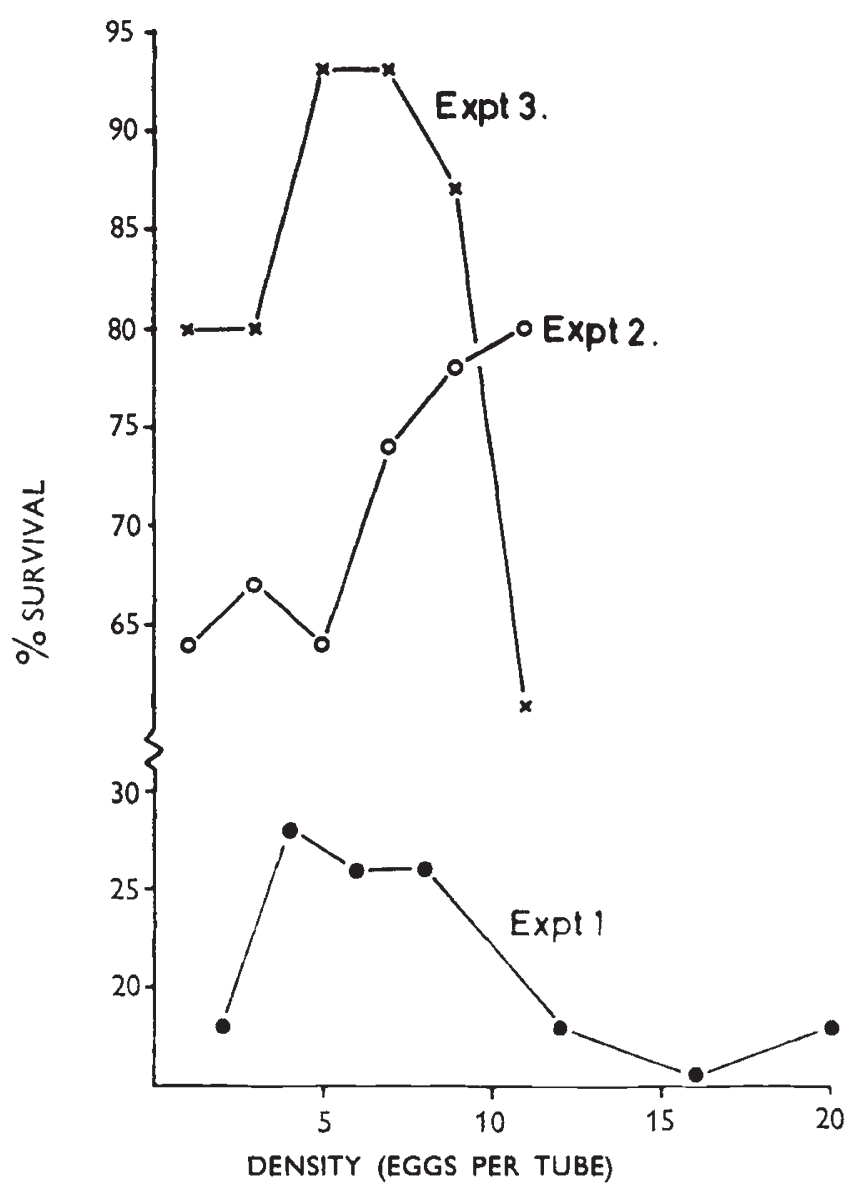

FIf. 1.--The effect of density on adult emergence in three experiments designed to investigate cooperation among larvæ of an inbred line of Drosophila melanogaster. 
neither the linear nor the quadratic components to be significant when . pared with either the residual mean square or the theoretical error. Neverucless, the negative linear component is responsible for the larger part of the sum of squares (SS).

TABLE 2

Adult emergence summed over all replicates at each density for experiments 2 and 3

\begin{tabular}{|c|c|c|c|c|c|c|c|}
\hline \multicolumn{7}{|c|}{ Density } & \multirow[b]{2}{*}{ Total } \\
\hline & $\mathfrak{I}$ & 3 & 5 & 7 & 9 & II & \\
\hline Replicates . & 44 & 15 & 9 & 6 & 5 & 4 & \\
\hline Total no. of eggs & 44 & 45 & 45 & $4^{2}$ & 45 & 44 & \\
\hline $\begin{array}{c}\text { Experiment } 1 \\
\text { Per cent. } \\
\text { angles }\end{array}$ & $\begin{array}{c}64 \\
53 \cdot 13\end{array}$ & $\begin{array}{c}67 \\
54 \cdot 94\end{array}$ & $\begin{array}{c}64 \\
53 \cdot 13\end{array}$ & $\begin{array}{c}74 \\
59 \cdot 34\end{array}$ & $\begin{array}{c}7^{8} \\
62 \cdot 03\end{array}$ & $\begin{array}{c}80 \\
63 \cdot 43\end{array}$ & $346 \cdot 0$ \\
\hline $\begin{array}{c}\text { Experiment } 3 \\
\text { Per cent. } \\
\text { angles }\end{array}$ & $\begin{array}{l}80 \\
63.43\end{array}$ & $\begin{array}{l}80 \\
63 \cdot 43\end{array}$ & $\begin{array}{l}93 \\
74 \cdot 66\end{array}$ & $\begin{array}{l}93 \\
74 \cdot 66\end{array}$ & $\begin{array}{l}87 \\
68.87\end{array}$ & $\begin{array}{l}61 \\
5^{1} \cdot 35\end{array}$ & $396^{\circ} 4$ \\
\hline
\end{tabular}

TABLE 3

Analyses of variance of angle data from experiments 2 and 3

\begin{tabular}{|c|c|c|c|c|c|c|}
\hline \multicolumn{7}{|c|}{ Experiment 2} \\
\hline Item & & $n$ & SS & M.S. & $x^{2}$ & $\mathbf{P}$ \\
\hline $\begin{array}{l}\text { Linear regression } \\
\text { Residual }\end{array}$ & . $\quad$. & $\begin{array}{l}I \\
4\end{array}$ & $\begin{array}{l}74 \cdot 24 \\
29 \cdot 41\end{array}$ & & $3 \cdot 99$ & 0.05 \\
\hline Total & . & 5 & ro3.65 & & & \\
\hline Theoretical error & . & $\infty$ & & เ8.59 & & \\
\hline
\end{tabular}

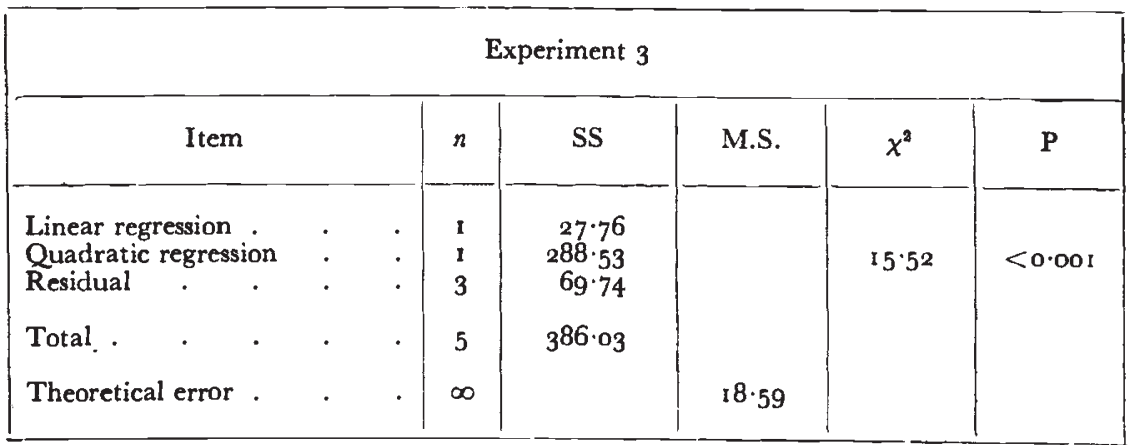


In the second and third experiments, egg densities per tube of $1,3,5,7$, 9 and II, were used. The data obtained expressed as percentages and angles, from these two experiments are shown in table 2 and graphically in fig. I (expt. 2 and 3 ) for percentages only. Analyses of variance of these data (transformed to angles) are shown in table 3 .

It can be seen that in experiment 2 there is a significant positive linear regression $(P=0.05)$ and in 3 a significant quadratic regression $(P<0.001)$ of viability on density, both of which are consistent with the cooperation hypothesis. In experiment 2 an increase in egg density has continued to raise the overall viability of the culture up to the maximum density used, I I eggs per tube. In experiment 3 , on the other hand, viability increases to a maximum at between 5-7 eggs per tube through the action of cooperation. Above this density, however, competition appears to take over, resulting in a decrease in viability.

The difference in average viability in the three experiments is probably a reflection of both the moisture content of the medium, which would affect hatchability, and also the extent of the fungal contamination.

The results are consistent with Mather's cooperation hypothesis and agree in general with the results of Lewontin, and Lewontin and Matsuo. As Mather suggested, however, cooperation, neutrality and competition appear to interact with the environment.

\title{
1. REFERENCES
}

LEWONTIN, R. 1955. The effects of population density and composition on viability in Drosophila Melanogaster. Evolution IX, I, 27-4I.

LEWONTIN, R., AND MATSUO. 1963. Interaction of genotypes determining viability in Drosophila buskii. Proc. N.A.S., 49, 2, 270-278.

MATHER, x. 196I. Competition and cooperation. Symp. Soc. Exp. Biol., I5, 264-28 I.

\section{DENSITY EFFECTS IN POLYMORPHIC LAND SNAILS}

\author{
D. F. OWEN
}

Department of Zoology, Makerere College, University of East Africa, Kampala, Uganda

Received 16.xi.64

THE shells of many species of land snails of the families Achatinidx and Helicidx may be variously patterned and coloured, and often it is possible to find several distinct forms within a single population. Intermediates may be rare or absent. Polymorphisms of this kind may be maintained in stable equilibrium if the fitness of the heterozygotes is greater than that of the homozygotes or if the fitness of the forms varies with their frequency in the population. The second possibility is especially likely if the colour forms are conspicuously different from each other and if the population is preyed upon by predators that recognise their prey by colour and pattern. In this paper I suggest that selective predation is important in maintaining the diversity present in certain land snail populations and that in addition the diversity depends, at least partly, upon the density of the population. 